\title{
DESAFIOS ENFRENTADOS NA IMPLEMENTAÇÃO DAS MEDIDAS DE PREVENÇÃO PARA CONTER O NOVO CORONAVÍRUS EM ÂFRICA: UMA REVISÃO SOBRE MEDIDAS ADOTADAS NA ÁFRICA DO SUL, ARGÉLIA E NIGÉRIA
}

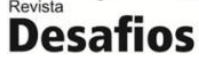

Challenges faced in implementing preventive measures to contain the new coronavirus in Africa: a review of measures taken in South Africa, Algeria and Nigeria

Desafios enfrentados en la implementación de medidas preventivas para contener el nuevo coronavirus en África: una revisión de las medidas tomadas en Sudáfrica, Argelia y Nigeria

João Viriato Mazalo $^{* 1}$, Bruno Mori ${ }^{2}$, Antônio Luiz Boechat ${ }^{1,2}$

${ }^{1}$ Programa de Pós-Graduação em Ciências da Saúde - Universidade Federal do Amazonas, Manaus- AM, Brasil.

${ }^{2}$ Programa de Pós-Graduação em Imunologia Básica e Aplicada - Universidade Federal do Amazonas, ManausAM, Brasil.

*Correspondência: Faculdade de Medicina, Universidade Federal do Amazonas, Rua Afonso Pena, 1053 - Centro, Manaus - AM, CEP: 69020-160. E-mail: joaomazalo@gmail.com.

Artigo recebido em 28/05/2020 aprovado em 03/11/2020 publicado em 12/03/2021.

\section{RESUMO}

A pandemia do COVID-19 é considerada a principal ameaça à saúde e o bem-estar de todos, a nível global, criando danos psicológicos, sociais e econômicos. Os países africanos têm sistemas de saúde frágeis, por este motivo, a África deve enfrentar a pandemia do COVID-19 como uma guerra a ser vencida e estar preparada para aumentar significativamente os gastos em saúde pública, criando uma cooperação múltipla que abrange todos os sectores essenciais. Esta pesquisa teve como objetivo analisar os desafios enfrentados na implementação das medidas de prevenção adotadas pelos três (3) países africanos mais afetados pelo COVID-19, nomeadamente África do Sul, Argélia e Nigéria. Para a realização desta revisão bibliográfica, foi necessário fazer buscas nas bases de dados Medline, Embase, SCIELO e outros recursos relevantes para elaboração do artigo. Nesta pesquisa, constatou-se que em alguns países Africanos, mesmo com as medidas de bloqueio impostas pelos governos locais para impedir a disseminação do vírus, trabalhadores informais vão as ruas praticar o comércio, situação que os colocam em risco de infecção pelo novo Coronavírus. Assim, torna-se imprescindível o governo criar auxílio emergencial ou disponibilizar cesta básica para os mais necessitados, evitando o descumprimento das diretivas estritas para combater a propagação do COVID-19.

Palavras-chave: África, COVID-19, prevenção.

\section{ABSTRACT}

The COVID-19 pandemic is considered the main threat to the health and well-being of everyone, globally, creating psychological, social and economic damage. African countries have fragile health systems, for this reason, Africa must face the COVID-19 pandemic as a war to be won and be prepared to significantly increase public health spending, creating multiple cooperation that covers all sectors essential. This research aimed to analyze the challenges faced in the implementation of the preventive measures adopted by the three (3) African countries most affected by COVID-19, namely South Africa, Algeria and Nigeria. To carry out this bibliographic review, it was necessary to search the Medline, Embase, SCIELO and other relevant resources for the preparation of the article. In this research, it was found that in some African countries, even with the blocking measures imposed by local 
governments to prevent the spread of the virus, informal workers take to the streets to practice commerce, a situation that puts them at risk of infection with the new coronavirus. Thus, it is essential for the government to create emergency aid or make basic food baskets available to the most needy, avoiding non-compliance with strict guidelines to combat the spread of COVID-19.

Keywords: Africa, COVID-19, prevention.

\section{RESUMEN}

La pandemia de COVID-19 se considera la principal amenaza para la salud y el bienestar de todos, a nivel mundial, creando daños psicológicos, sociales y económicos. Los países africanos tienen sistemas de salud frágiles, por esta razón, África debe enfrentar la pandemia COVID-19 como una guerra que se ganará y estar preparado para aumentar significativamente el gasto público en salud, creando una cooperación múltiple que cubra todos los sectores. esencial. Esta investigación tuvo como objetivo analizar los desafios enfrentados en la implementación de las medidas preventivas adoptadas por los tres (3) países africanos más afectados por COVID-19, a saber, Sudáfrica, Argelia y Nigeria. Para llevar a cabo esta revisión bibliográfica, fue necesario buscar en Medline, Embase, SCIELO y otros recursos relevantes para la preparación del artículo. En esta investigación, se descubrió que en algunos países africanos, incluso con las medidas de bloqueo impuestas por los gobiernos locales para evitar la propagación del virus, los trabajadores informales salen a las calles para practicar el comercio, una situación que los pone en riesgo de infección con el nuevo coronavirus. Por lo tanto, es esencial que el gobierno cree ayuda de emergencia o ponga canastas de alimentos básicos a disposición de los más necesitados, evitando el incumplimiento de pautas estrictas para combatir la propagación de COVID-19.

Descriptores: África, COVID-19, prevención.

\section{INTRODUÇÃO}

Em dezembro de 2019, uma nova pandemia surgiu em Wuhan, província de Hubei, China e foi nomeada pela Organização Mundial de Saúde (OMS) como doença do novo coronavírus (COVID-19) e vírus síndrome respiratória aguda grave coronavírus 2 (SARS-CoV-2) (CHAKRABORTY; MAITY, 2020).

O ritmo acelerado de novos casos de infecção a nível mundial, fez com que a OMS decretasse emergência sanitária global por conta do novo coronavírus. Na África os primeiros casos de COVID-19 foram importados dos continentes Europeu e Asiático, devido ao maior número de tráfego aéreo dessa região para África, em turismo e atividades empresariais. Foi no dia 14 de fevereiro de 2020 que foi reportado o primeiro caso de infecção em África, concretamente no Egito, onde após a confirmação deste caso testou-se todos os indivíduos que tiveram contato com o homem infectado e todos tiveram resultados negativo (WORLD HEALTH ORGANIZATION, 2020a).

Até o dia 24 de maio de 2020, o continente Africano registou cerca de 77295 casos confirmados e 2073 mortes, sendo considerada a região com menos casos confirmados pelo COVID-19 a nível global. Segundo os dados da OMS, os três (3) países africanos mais afetados pelo COVID-19 são: África do Sul 21 343, Argélia 8113 e Nigéria com cerca de 7526 casos confirmados (WORLD HEALTH ORGANIZATION, 2020b). Os números que o continente apresenta, podem não refletir na totalidade a extensão da disseminação do vírus devido ao baixo número de kits de testagem (KARAMOUZIAN; MADANI, 2020). Evidências preliminares apontam que a pandemia de COVID-19 pode ser parcialmente suprimida com o aumento da temperatura e da umidade (WU et al., 2020). Tendo em conta essa evidência, pode-se supor que o clima tropical tem ajudado o continente a conter a propagação do COVID-19, uma vez que grande parte da África predomina o clima tropical. 
Para conter o COVI-19, é importante compreender que o diagnóstico precoce é eficaz no controle da doença, considerando os riscos de transmissão potencialmente representados por indivíduos assintomáticos. Os países Africanos apresentam maior dificuldade em adquirir kits para testar um maior número de pessoas, obrigando os governos africanos a restringir os testes a indivíduos suspeitos e potencialmente em risco de contrair o COVID-19 (ADEPOJU, 2020).

Apesar dos esforços realizados para evitar a propagação do COVID-19, o mundo deparasse com dificuldades para criar a cura desta pandemia que a cada dia que passa só tem aumentado o número de mortos em várias partes do mundo. É nesse contexto que a África também, tem-se preparado para responder de forma imediata, progressiva e adaptável, apesar das limitações de recursos econômicos que o continente enfrenta (SENGHORE et al., 2020).

A OMS, através dos seus representantes em alguns países Africanos tem acompanhado de perto a situação epidemiológica da pandemia, onde realiza ações em coordenação com os Ministérios de Saúde dos respectivos países. Houve uma resposta rápida à epidemia de COVID-19 dos sistemas de saúde pública da África, muito antes de qualquer caso de COVID-19 ter sido relatado na África, graças ao esforço coletivo. Assim, os países Africanos têm estado em alerta máximo para detectar e isolar quaisquer casos importados de COVID-19 (KAPATA et al., 2020).

Com intuito de apoiar a África a ultrapassar as dificuldades a OMS e parceiros enviam matérias médicos necessários a todas as nações africanas na luta contra o COVID-19, através dos "voos solidários" da Organização das Nações Unidas (ONU), liderados pela OMS, Programa Mundial de Alimentos (PMA), União Africana (UA) e Centro para a Prevenção e Controlo de
Doenças da União Africana (CDC) da África (WORLD HEALTH ORGANIZATION, 2020c). Alguns países Africanos têm dificuldade de implementar as medidas de prevenção do COVID-19 por viver um conflito político militar, um exemplo concreto é o caso da Líbia (DAW, 2020).

Os países Africanos estão correndo contra o tempo de modo a minimizar a propagação do vírus, adotando medidas preventivas, que vão desde a testagem, tratamento de pacientes infectados, rastreamento de contatos, limitando viagens, colocando cidadãos em quarentena e cancelando grandes reuniões, como eventos esportivos, shows, cinema e escolas. O COVID-19 para além de afetar o sector de saúde, ele tem o potencial de criar devastadoras crises sociais, econômicas e políticas que deixarão cicatrizes profundas, uma vez que, todos os dias, as pessoas estão perdendo emprego e renda, sem nenhuma maneira de saber quando a normalidade retornará (PROGRAMA DE DESENVOLVIMENTO DAS NAÇÕES UNIDAS, 2020).

A África enfrenta vários desafios que impactam diretamente na implementação das medidas de prevenção, visto que uma parte considerável da população Africana, vive de trabalho informal, diante das medidas restritivas de circulação e comércio, alguns países como é o caso de Moçambique, após decretar o estado de emergência no dia 30 de março, comerciantes informais que vendem produtos não essências como bebidas alcoólicas, violavam as medidas de prevenção e criavam uma aglomeração de pessoas nos seus bares, violando o decreto presidencial, alegando que abriam os seus bares para não passar fome (PRESIDÊNCIA DA REPÚBLICA DE MOÇAMBIQUE, 2020). 
É importante realçar, que embora o continente Africano tenha sido alertado de forma antecipada, os números não mentem, a cada dia que passa tem surgido novos casos confirmados e mortes pelo COVID-19, ainda que, as medidas de prevenção consideradas eficazes estejam a ser implementadas por alguns países africanos. Deste modo, considerando que a implementação de medidas para conter o COVID-19 foram eficazes na China, é crucial conscientizar os africanos sobre a necessidade de controlar a infecção, bloquear a transmissão e impedir a disseminação de casos novos do COVID-19, tendo em conta, que a pandemia está se movendo como ciclone que pode devastar vidas, bem como a economia. Sendo assim, torna-se relevante, analisar os desafios enfrentados na implementação das medidas de prevenção adotadas pelos três (3) países africanos mais afetados pelo COVID-19, nomeadamente África do Sul, Argélia e Nigéria.

\section{MATERIAIS E MÉTODOS}

Para a realização desta revisão bibliográfica, foi necessário fazer buscas de publicações nas bases de dados Medline (via PubMed), Embase (via ScienceDirect) e biblioteca virtual Scientific Electronic Library Online (SCIELO), com as seguintes palavraschaves: "covid-19" AND " Africa ", " covid-19 " AND " prevention ", " coronavirus disease " AND " Africa ", " coronavirus infections " AND "Africa ", "2019 novel coronavirus infection" AND "Isolation", "2019 novel coronavirus infection" AND "quarantine", "2019 novel coronavirus infection" AND "social distancing", "covid-19" AND " South Africa ", "covid-19" AND " Algeria ", "covid-19" AND " Nigeria". As informações foram complementadas pelas bases de dados oficiais da Organização Mundial de Saúde (OMS), governos
Africanos e Ministérios de Saúde de alguns países citados nesta pesquisa bibliográfica.

\section{REVISÃO BIBLIOGRÁFICA}

Diante do alastramento da pandemia do COVID-19, o mundo viu-se obrigado a recorrer à implementação rigorosa das medidas de saúde pública. A África não ficou alheia, e os seus governantes em coordenação com os respectivos Ministérios de Saúde, implementaram medidas clássicas de saúde pública para conter essa pandemia. Dentre essas medidas podemos destacar: isolamento social, quarentena, lockdown e distanciamento social.

\section{Isolamento}

Isolamento é a separação de pessoas doentes com doenças contagiosas, de pessoas não infectadas, para proteger pessoas não infectadas, e geralmente ocorre em ambientes hospitalares (WILDER-SMITH; FREEDMAN, 2020).

\section{Quarentena}

Quarentena é a restrição de movimento de pessoas que se presume terem sido expostas a uma doença contagiosa, mas não estão doentes, porque não foram infectadas ou porque ainda estão no período de incubação. Ela pode ser aplicada no nível individual ou em grupo e geralmente envolve restrição à casa ou a uma instalação designada, dependendo da situação, sendo que em casos extremos pode deixar de ser voluntaria e passar a ser obrigatória (CETRON; LANDWIRTH, 2005).

\section{Distanciamento social}

O distanciamento social é aplicado para reduzir as interações entre pessoas em uma comunidade mais ampla, isto é, para evitar a proximidade de indivíduos 
que podem ser infecciosos, mas ainda não foram identificados e, portanto, ainda não isolados. Em caso de necessidade as estruturas locais, podem determinar a aplicação do bloqueio (em inglês, lockdown), uma intervenção rigorosa aplicada a todos indivíduos da cidade ou região através da proibição das pessoas saírem dos seus domicílios, exceto para a aquisição de suprimentos básicos ou ida a serviços de urgência (WILDER-SMITH; FREEDMAN, 2020).

\section{Evidência científica das medidas de prevenção de COVID-19}

Num contexto atual em que o mundo enfrenta a ameaça cada vez mais alarmante da pandemia do COVID-19, vários pesquisadores tentam achar a cura ou vacina antiviral do vírus síndrome respiratória aguda grave coronavírus 2 (SARS-CoV-2). Num estudo realizado por (FERGUSON; GILANI, 2020), constatou-se que a eficácia de qualquer intervenção isolada seja limitada, sendo por isso, recomendável a aplicação de políticas ótimas de mitigação (combinando isolamento domiciliar de casos suspeitos, quarentena domiciliar, distanciamento social de idosos e outras pessoas com maior risco de doença grave), que podem reduzir o pico da demanda de assistência médica em $2 / 3$ e mortes pela metade. Num outro estudo realizado na China em Wuhan, observou-se que um confinamento mais rigoroso de pessoas em áreas de alto risco tem potencial para diminuir a propagação do COVID-19 (LAU et al., 2020).

\section{África}

Os países africanos têm sistemas de saúde frágeis e isso continua sendo uma fonte de preocupação, deixando as autoridades em alerta máxima, especialmente nos países com alto índices de casos confirmados pelo COVID-19. A contenção da propagação e a redução do impacto econômico da pandemia do COVID-19 exigirá uma abordagem e cooperação múltipla de todas as partes. A África deve enfrentar a pandemia do COVID-19 como uma luta a ser vencida e estar preparado para aumentar significativamente os gastos em saúde pública (ATAGUBA, 2020).

Muitos países africanos continuam a aplicar diretivas estritas para combater a propagação do vírus, pouca atenção tem sido dada aos efeitos das diretivas de bloqueio na capacidade das pessoas de se alimentarem e ao clamor resultante da maioria dos pobres urbanos levou muitos governos a pensar nas provisões de emergência de alimentos, algumas das quais se transformaram em enormes escândalos de corrupção e fornecimento de alimentos de baixa qualidade. Esse efeito é muito sentido entre a maioria da população urbana que trabalha no setor informal e depende da renda casual diária, o que significa que eles vivem todos os dias de sua capacidade para poder pagar uma refeição diária, sendo esse um dos principais desafios enfrentados na implementação das medidas de prevenção para conter o novo coronavírus em África (MUKIIBI, 2020).

\section{Os três (3) países Africanos mais afetados pelo COVID-19}

\section{1. África do Sul}

África do Sul teve o primeiro caso confirmado do COVID-19 no dia 5 de março de 2020. Desde então, tem desdobrado esforços para conter o avanço desta pandemia, que consistem em ações para evitar a transmissão e a infecção do vírus síndrome respiratória aguda grave coronavírus 2 (WORLD HEALTH ORGANIZATION, 2020d). 
Após o primeiro caso de infecção confirmado pelo COVID-19, o Governo Sul Africano representado ao mais alto nível pelo Presidente da República Sul Africana, declarou Estado de Desastre nos termos da seção 27 da Lei de Gerenciamento de Desastres n ${ }^{\circ} 57$ de 2002 e tomou as seguintes medidas preventivas:

- Proibição de viagem de estrangeiros de países de alto risco, como Itália, Irã, Coréia do Sul, Espanha, Alemanha, EUA, Reino Unido e China a partir de 18 de março de 2020.

- Proibição de reunir 100 pessoas.

- Determinou que em caso de recusa de exame médico, profilaxia, tratamento, isolamento ou quarentena, o indivíduo pode então ser colocada em isolamento ou em quarentena obrigatória por um período de 48 horas.

- Encerramento de escolas de 18 de março de 2020 a 15 de abril de 2020.

- Suspensão de visitas por 30 dias a centros correcionais, centros de detenção preventiva, celas, centros de detenção militar e instalações do Departamento de Desenvolvimento Social.

- Limitação da venda, distribuição ou transporte de bebidas alcoólicas, neste contexto devem ser encerradas com efeito imediato ou acomodar no máximo 50 pessoas (NKONKI; FONN, 2020).

Até o dia 24 de maio de 2020, a África do Sul reportou 21343 casos confirmados e 407 mortes pelo COVID-19, um cenário alarmante, que coloca o país no topo dos países infectados em África, que levanta preocupações, bem como incertezas sobre o futuro do vírus em África visto que é considerado o país com melhor recursos econômicos para lidar com a pandemia (WORLD HEALTH ORGANIZATION, 2020b).
A África do Sul possui o sistema de saúde mais robusto da África, mas é definido pela desigualdade, onde apenas $16 \%$ da população pode pagar seguro médico e têm acesso aos melhores cuidados de saúde do setor privado, enquanto o resto depende de recursos públicos. Para combater o COVID-19 o governo anunciou o bloqueio em 27 de março, quando a África do Sul tinha apenas 402 infecções COVID-19 conhecidas e nenhuma morte. A quarentena, o isolamento, bem como o distanciamento físico forçado e o bloqueio antecipado conseguiram atrasar a transmissão, mais havia cada vez mais a necessidade de ampliar os testes na comunidade, com foco nos mais pobres em particular. Inicialmente, os critérios para o teste eram limitados a pessoas sintomáticas que haviam viajado recentemente de um país de alto risco ou que entraram em contato com alguém em risco de COVID19. Porém, com o início da transmissão local, os testes aumentaram com a introdução da triagem comunitária (WADVALLA, 2020).

No dia 1 de maio entrou em vigor o nível 4 da declaração de estado de desastre e a partir do dia 1 de junho estrará em vigor o nível 3 (SOUTH AFRICAN GOVERNMENT, 2020).

\section{Argélia}

No dia 25 de fevereiro de 2020, a Argélia registou o primeiro caso de infecção pelo vírus síndrome respiratória aguda grave coronavírus 2 (SARS-CoV-2), tornando-se no segundo país Africano afetado pela pandemia, depois do Egito (WORLD HEALTH ORGANIZATION, 2020e).

Após a identificação do primeiro caso confirmado, o Ministério da Saúde, População e Reforma Hospitalar da Argélia, fortaleceu o sistema de prevenção, monitoramento e controle em todos os pontos de entrada. Em África o Egito, Argélia e África 
do Sul são os países com maior risco de importar o COVID-19, devido à frequentes viagens aéreas com os países mais afetados. Esses três países também estão entre os mais bem equipados do continente para detecção e gerenciamento precoce de casos (MINISTÉRIO DA SAÚDE DA POPULAÇÃO E REFORMA HOSPITALAR, 2020).

No dia 24 de maio de 2020 a Argélia registou 8113 casos confirmados e 592 mortes pelo covid-19, sendo o país africano com mais mortes até ao momento (WORLD HEALTH ORGANIZATION, 2020b).

Com um aumento de números de casos confirmados pelo COVID-19, a Argélia começou a produzir na primeira quinzena de maio, kits para testes do novo coronavírus, sendo inicialmente produzidas 200 mil unidades por semana, um teste que apresenta resultado em 15 minutos após a aplicação (AGÊNCIA DE NOTÍCIAS BRASIL-ÁRABE, 2020).

O governo Argelino depois da identificação dos primeiros casos começou a implementar um conjunto de medidas preventivas para aumentar o distanciamento social e limitar a propagação do vírus. Essas medidas consistem no cancelamento de viagens, isolamento de cidadãos repatriados, a restrição de todas as reuniões, fechamento de escolas, universidades e todos instituições educacionais, mesquitas e locais de culto e suspensão de orações coletivas, suspensão de todas as transportes públicos comuns e tráfego ferroviário. $\mathrm{O}$ aumento de números de casos confirmados está associado a decisão do governo de aliviar essas medidas para razões econômicas e sociais, uma vez que estes dias coincidem com o começo do mês sagrado do Ramadã. Por isso, para ultrapassar esses desafios na implementação dessas medidas o governo deve usar todos os seus recursos para o respeito de distanciamento social no mês sagrado do Ramadã, e também para garantir necessidades vitais para a baixa renda e as famílias carentes (LOUNIS, 2020). É importante não só adoptar essas medidas mais também, bons hábitos de higiene, de modo a evitar infecções pelo vírus e a sobrecarga no sistema de saúde (HAMIDOUCHE, 2020).

Para que as medidas sejam eficientes é necessário compreender a razão do mau cumprimento das recomendações e regras, bem como tomar medidas exatas para melhorar e reforçar cada vez mais a prevenção contra o COVID-19 na Argélia (BOUKHATEM, 2020).

\section{Nigéria}

A Nigéria é uma das nações negras mais populosas do mundo, que teve o primeiro caso confirmado em 27 de fevereiro de 2020. Este caso foi importado da Europa. Tratava-se de um cidadão italiano que voltou de Milão, que foi testado e deu positivo para o COVID19. De imediato fez-se o rastreamento para identificar os cidadãos que tinham entrado em contato com o primeiro paciente infectado. Após a confirmação do primeiro caso de COVID-19 o Governo da Nigéria, através do Ministério Federal da Saúde, orientou que todos os cidadãos, deviam cuidar da saúde, manter a higiene (lavar as mãos com álcool ou sabão), manter o distanciamento social de 1,50 metros de pessoas que estejam tossindo, cobrir a boca ao tossir com cotovelo e disponibilizou plataforma telefônica para os pacientes que apresentarem sintomas ou tiverem dúvidas (FEDERAL MINISTRY OF HEALTH, 2020a).

Em 7 de maio o Ministério da Saúde, anunciou a criação de 21 Laboratórios de Testes que estarão em operação em todo o país e um programa de treinamento intensivo para minimizar o risco de infecção de pessoal de saúde, que incluía pessoal não médico, como faxineiros, carregadores e guardas de segurança, especialmente nos centros de isolamento e tratamento 
do COVID-19. Nesse mesmo período, foram repatriados cidadãos nigerianos e todos entraram em quarentena supervisionada obrigatória de 14 dias, em 2 hotéis designados, de acordo com os protocolos estabelecidos (FEDERAL MINISTRY OF HEALTH, 2020b).

Em 24 de maio de 2020 a Nigéria registou um total de 7562 casos confirmados e 221 mortes pelo COVID-19, tornando-se no terceiro país Africano mais afetado pela pandemia (WORLD HEALTH ORGANIZATION, 2020b). A cada dia que passa os números de infectados vem aumentando na Nigéria, e o atual sistema nacional de saúde, não consegue responder efetivamente às crescentes necessidades de pacientes já infectados que necessitam de internação em unidades de terapia intensiva pela síndrome respiratória aguda grave (SARS COV-2). Apesar do índice de mortalidade pelo COVID-19 ser baixo, a Nigéria tem pessoas vulneráveis com doenças sistêmicas (diabetes, hipertensão) e cerca de 6,4 milhões de pessoas com idade> 65 anos, consideradas grupos risco de infecção (OHIA; AHMAD, 2020).

A Nigéria como alguns países Africanos, não se depara só com a luta do COVID-19, mais também com a extrema pobreza. No dia 30 de março o Governo Federal da Nigéria aplicou um bloqueio inicial de duas semanas para três (3) dos 36 estados (Lagos, Ogun e Abuja). Em 13 de abril estendeu por mais duas semanas, após esse anuncio criou um mal-estar dentro da população, que vive de comercio informal, pois, as pessoas temiam morrer de fome. Para tentar resolver essa preocupação o governo anúncio o desembolso de fundos e itens alimentares para os mais necessitados. Mas a realidade no terreno está muito longe das promessas feitas, porque apenas uma pequena proporção da população recebeu algum apoio, em consequência disso um grande número de cidadãos desobedeceu à ordem de bloqueio na esperança de fazer vendas ou tentar ganhar dinheiro mas eles foram presos pela polícia (KALU, 2020).

Um das grandes limitações da Nigéria é o número insuficientemente de leitos e atendimento clínico associado para apoiar aqueles que poderiam precisar de isolamento e quarentena se ocorrerem ciclos locais de transmissão do COVID-19 no país, especialmente dos pacientes em estado crítico, que necessitem de internamento (EBENSO; OTU, 2020).

\section{CONCLUSÃO}

Os países Africanos enfrentam vários desafios na implementação das medidas de prevenção adotadas, desde a falta de recursos econômicos, o número reduzido de profissionais de saúde, aliados à fome, à pobreza, que dificultam não só a obtenção de kits suficientes de COVID-19, mais também a implementação das medidas de prevenção, visto que, existe um número considerável de indivíduos que violam as medidas de restrição impostas pelos governos locais para impedir a propagação do vírus, para praticar o comercio informal nas ruas, um ponto chave de propagação do vírus . Como consequência disso, tem si notado, que a cada dia que passa, a população tem pressionado os governos locais para reabrir as cidades em confinamento, permitir o comércio informal, para que toda a convivência volte ao normal, o que é impossível quando se está diante duma pandemia dessa proporção.

Nesse contexto, torna-se imprescindível o governo criar auxílio emergencial ou disponibilizar cesta básica para os mais necessitados, que vivem da renda diária, de modo a ficarem em casa. Também é importante consciencializar cada vez mais a população, sobre a importância de seguir as orientações da 
Organização Mundial de Saúde, de modo a garantir que essas estratégias sejam cumpridas na integra.

Por fim, é crucial fortalecer os sistemas de testagem, tornando-os mais abrangentes e inclusivos, possibilitando a identificação precoce dos pacientes com COVID-19, criando atendimento eficazes, eficiente, gratuitos e abrangentes para impedir a transmissão e disseminação descontrolada da doença na África.

\section{AGRADECIMENTO}

Todos os autores declararam não haver qualquer potencial conflito de interesses referente a este artigo.

\section{REFERÊNCIAS}

ADEPOJU, P. News Africa's struggle with inadequate COVID-19 testing. The Lancet Microbe, v. 1, n. 1, p. e12, 2020.

AGÊNCIA DE NOTÍCIAS BRASIL-ÁRABE. Argélia começou a produzir kits de testes de covid19. Disponível em: <https://anba.com.br/argeliacomecou-a-produzir-kits-de-testes-de-covid-19/> .

Acesso em: 25 maio. 2020.

ATAGUBA, J. E. COVID-19 Pandemic, a War to be Won: Understanding its Economic Implications for Africa. Applied Health Economics and Health Policy, n. 0123456789, p. 20-23, 2020.

BOUKHATEM, M. N. Novel Coronavirus Disease 2019 (COVID-19) Outbreak in Algeria: A New Challenge for Prevention. J Community Med Health Care, v. 5, n. 1, p. 1035, 2020.

CETRON, M.; LANDWIRTH, J. Public health and ethical considerations in planning for quarantine. Yale Journal of Biology and Medicine, v. 78, n. 5, p. 325330, 2005.

CHAKRABORTY, I.; MAITY, P. COVID-19 outbreak: Migration, effects on society, global environment and prevention. Science of the Total Environment, v. 728, p. 138882, 2020.

DAW, M. A. Preliminary epidemiological analysis of suspected cases of corona virus infection in Libya. Travel Medicine and Infectious Disease, n. March, p. 101634, 2020.

EBENSO, B.; OTU, A. Can Nigeria contain the COVID-19 outbreak using lessons from recent epidemics? The Lancet Global Health, n. 20, p. 30101, 2020.

FEDERAL MINISTRY OF HEALTH. MINISTER

OF HEALTH: FIRST CASE OF COVID-19 CONFIRMED IN NIGERIA. Disponível em: $<$ https://www.health.gov.ng/index.php?option=com_k $2 \&$ view=item $\&$ id=613:health-minister-first-case-ofcovid-19-confirmed-in-nigeria>. Acesso em: 25 maio. 2020a.

FEDERAL MINISTRY OF HEALTH. 21 LABORATORIES NATIONWIDE ARE NOW OPERATIONAL FOR COVID-19 TESTING - DR. EHANIRE. Disponível em: $<$ https://www.health.gov.ng/index.php?option=com_k $2 \&$ view=item \&id=661:21-laboratories-nationwideare-now-operational-for-covid-19-testing-dr-ehanire> . Acesso em: 25 maio. 2020b.

FERGUSON, N.; GILANI, G. N. Report 9: Impact of non-pharmaceutical interventions (NPIs) to reduce COVID19 mortality and healthcare demand. [s.l: s.n.].

HAMIDOUCHE, M. COVID-19 Epidemic in Algeria: Assessment of the implemented preventive strategy. medRxiv, n. April, p. 14, 2020.

KALU, B. COVID-19 in Nigeria: a disease of hunger. The Lancet. Respiratory medicine, v. 2600, n. 20, p. 19-20, 2020.

KAPATA, N. et al. Is Africa prepared for tackling the COVID-19 (SARS-CoV-2) epidemic. Lessons from 
past outbreaks, ongoing pan-African public health efforts, and implications for the future. International Journal of Infectious Diseases, v. 93, p. 233-236, 2020.

KARAMOUZIAN, M.; MADANI, N. Comment COVID-19 response in the Middle East and north Africa: challenges and paths forward. The Lancet Global Health, v. 2019, n. 20, p. 2019-2020, 2020.

LAU, H. et al. The positive impact of lockdown in Wuhan on containing the COVID-19 outbreak in China. Journal of travel medicine, n. March, p. 1-7, 2020.

LOUNIS, M. A Descriptive Study of the Current Situation of COVID-19 in Algeria. v. 17, n. 6, p. 1720, 2020.

\section{MINISTÉRIO DA SAÚDE DA POPULAÇÃO E} REFORMA HOSPITALAR. INFORMAÇÕES. Disponível em: > فبر اير --25/25:/covid19.sante.gov.dz/2020/02/25/25 2020/>. Acesso em: 25 maio. 2020.

MUKIIBI, E. COVID - 19 and the state of food security in Africa. Agriculture and Human Values, $n$. 0123456789, 2020.

NKONKI, L.; FONN, S. Decisive and strong leadership and intersectoral action from South Africa in response to the COVID-19 virus. South African Medical Journal, v. 110, n. 5, p. 339, 27 mar. 2020.

OHIA, C.; AHMAD, T. COVID-19 and Nigeria: Putting the realities in context. International Journal of Infectious Diseases, v. 95, p. 279-281, 2020.

PRESIDÊNCIA DA REPÚBLICA DE MOÇAMBIQUE. Comunicação de Sua Excelência Filipe Jacinto Nyusi, Presidente da República de Moçambique, à Nação sobre a situação da Pandemia do Corona Vírus - COVID - 19. Disponível em: $<$ https://www.presidencia.gov.mz/por/Media/Files/10
0-COVID_Comunicacao-a-Nacao-3003020>. Acesso em: 23 maio. 2020.

PROGRAMA DE DESENVOLVIMENTO DAS NAÇÕES UNIDAS. Pandemia do covid-19 A humanidade precisa de liderança e solidariedade para derrotar o coronavírus. Disponível em: <https://www.undp.org/content/undp/en/home/corona virus.html>. Acesso em: 23 maio. 2020.

SENGHORE, $M$. et al. Leveraging Africa's preparedness towards the next phase of the COVID-19 pandemic. The Lancet Global Health, v. 2019, n. 20, p. 2019-2020, maio 2020.

SOUTH AFRICAN GOVERNMENT. COVID-19 Novo coronavírus. Disponível em: <https://www.gov.za/Coronavirus>. Acesso em: 25 maio. 2020.

WADVALLA, B. Covid-19: decisive action is the hallmark of South Africa's early success against coronavirus. BMJ, v. 1623, n. April, p. m1623, 24 abr. 2020.

WILDER-SMITH, A.; FREEDMAN, D. O. Isolation, quarantine, social distancing and community containment: Pivotal role for old-style public health measures in the novel coronavirus (2019-nCoV) outbreak. Journal of Travel Medicine, v. 27, n. 2, p. $1-4,2020$.

WORLD HEALTH ORGANIZATION. Coronavirus disease 2019 (COVID-19) Situation Report - 26. [s.1: s.n.]. Disponível em: $<$ https://www.who.int/docs/defaultsource/coronaviruse/situation-reports/20200215sitrep-26-covid-19.pdf?sfvrsn=a4cc6787_2>. WORLD HEALTH ORGANIZATION. Coronavirus disease (COVID-19) Situation Report - 125 Data. [s.l: s.n.]. Disponível em: $<$ https://www.who.int/docs/defaultsource/coronaviruse/situation-reports/20200524- 
covid-19-sitrep-125.pdf?sfvrsn=80e7d7f0_2>.

WORLD HEALTH ORGANIZATION. How is WHO

responding to COVID-19? Disponível em:

$<$ https://www.who.int/emergencies/diseases/novel-

coronavirus-2019/who-response-in-countries>. Acesso

em: 23 maio. 2020c.

WORLD HEALTH ORGANIZATION. Coronavirus

disease 2019 (COVID-19) Situation Report - 46. [s.l:

s.n.]. Disponível em:

$<$ https://www.who.int/docs/default-

source/coronaviruse/situation-reports/20200306-

sitrep-46-covid-19.pdf?sfvrsn=96b04adf_4>.

WORLD HEALTH ORGANIZATION. Coronavirus

disease 2019 (COVID-19) Situation Report - 37. [s.1:

s.n.]. Disponível em:

$<$ https://www.who.int/docs/default-

source/coronaviruse/situation-reports/20200226-

sitrep-37-covid-19.pdf?sfvrsn=2146841e_2>.

WU, Y. et al. Effects of temperature and humidity on

the daily new cases and new deaths of COVID-19 in 166 countries. Science of the Total Environment, v.

729, p. 1-7, 2020. 